\title{
NILAI MORAL DARI ASPEK HUBUNGAN MANUSIA DENGAN MANUSIA DALAM KUMPULAN CERITA RAKYAT DAERAH JAMBI KARYA THABRAN KAHAR
}

\author{
Abdoel Gafar ${ }^{1}$, Nurul Sarah ${ }^{2}$ \\ Program Studi Pendidikan Bahasa dan Sastra Indonesia, \\ Fakultas Keguruan dan Ilmu Pendidikan, Universitas Batanghari, \\ Jambi \\ gafar3r@yahoo.co.id \\ sarahnur507@gmail.com
}

\begin{abstract}
The research is aimed at describing the moral value aspects of human-to-human relationships in Kumpulan Cerita Rakyat Daerah Jambi by Thabran Kahar. The moral value consists of aspects (1) caring for others, (2) helping, (3) deliberation, (4) living together, (5) forgiving, (6) keep on promise, (7) appreciating others. This research includes descriptive qualitative types. Qualitative descriptive describes an event with words or images of objects with actual circumstances. The data sources in this research are words, sentences, quotations or expressions that can be found in the dialogue of the characters in Kumpulan Cerita Rakyat Daerah Jambi by Thabran Kahar. Based on the results of this research, it can be concluded that aspects of the moral value of human relationships with other human beings are contained in the Kumpulan Cerita Rakyat Daerah Jambi by Thabra Kahar. The data showed that there are 60 expressions that are divided into seven aspects of moral values including: caring for each other as many as 14 quotations, please help as many as 12 quotations, deliberation as many as 9 quotations, living together as many as 8 quotations, forgiving as many as 6 quotes, keep on promise as many as 4 quotations, and respect others as many as 7 quotations.
\end{abstract}

Keywords: value, moral, folklore

\footnotetext{
${ }^{1}$ Dosen Program Studi Pendidikan Bahasa dan Sastra Indonesia, Fakultas Keguruan dan Ilmu Pendidikan, Universitas Batanghari, Jambi

${ }^{2}$ Mahasiswa Program Studi Pendidikan Bahasa dan Sastra Indonesia, Fakultas Keguruan dan Ilmu Pendidikan, Universitas Batanghari, Jambi
} 


\section{PENDAHULUAN}

Ragam budaya di Indonesia sangat banyak. Keragaman budaya ini karena banyaknya budaya yang ada di setiap provinsi di Indonesia. Kultur yang beragam menjadikan Indonesa kaya akan budaya. Khusunya di provinsi Jambi terdapat banyak kebudayaan yang bisa dinikmati. Ragam budaya itu dapat dinikmati melalui tarian, upacar-upacara adat, seloko dan, cerita-cerita rakyat yang ada di provinsi Jambi. Menurut pendapat Rahima (2017:251) Masyarakat Melayu Jambi merupakan bagian dari bangsa Indonesia memiliki kepribadian dan nilainilai budaya yang tinggi yang tercermin dari sastra lisan khususnya cerita rakyat.

Selain cerita rakyat yang mencakup seni sastra tulis dan lisan. kebudayaan provinsi Jambi beragam dalam hal kebudayaan yang senantiasa dipertahankan oleh masyarakatnya. Ragam kebudayaan Jambi misalnya rumah adat, pakaian adat, tarian-tarian tradisional, seni musik dan teater, lagulagu daerah, kerajinan rakyat Jambi, upacara-upacara tradisional Jambi, dan senjata tradisional Jambi.

Cerita rakyat adalah cerita yang berkembang pada masyarakat."Cerita rakyat didefinisikan sebagai kesusastraan dari rakyat, yang penyebarannya pada umumnya melalui tutur kata atau lisan" (Danandjaja, 2002: 5). Dapat dipahami bahwa cerita rakyat merupakan kesustraan dari rakyat yang berasal dan berkembang dalam masyarakat pada masa lampau. Cerita rakyat menjadi ciri khas setiap bangsa yang memiliki budaya beraneka ragam mencakup kekayaan budaya dan sejarah yang dimiliki masingmasing bangsa.

Cerita rakyat Jambi mengisahkan hal-hal yang berkaitan dengan cerita- cerita, dongeng-dongeng yang berhubungan dengan imajinasi dan kejadian yang ada pada masyarakat masa dahulu di daerah Jambi. Dewasa ini budaya Jambi mulai tersingkirkan dengan masuknya budaya-budaya asing dan terbukanya ilmu pengetahuan teknologi yang semakin maju. Akibatnya kebudayaan Jambi mulai terpinggirkan termasuk sastra. Hal ini terlihat dari risaunya Budayawan Jambi tentang tergerusnya budaya-budaya Jambi. Dikhawatirkan nilia-nilai budaya yang berisi tentang nilai luhur masyarakat Jambi akan hilang dan punah. Seperti dikemukan oleh Djunadi T. Noer di dalam seminar budaya Jambi di Kantor bahasa pada bulan bahasa tahun 2017, beliau mengatakan bahwa budaya Jambi mulai tersingkirkan dengan masuknya budaya-budaya asing termasuk tentang cerita rakyat Jambi.

Cerita rakyat Jambi merupakan bagian dari kebudayaan kearifan lokal. Kedudukan cerita rakyat dalam beberapa tahun terakhir semakin tergeser akibat kemajuan zaman dan teknologi. Beragam bentuk tradisi kebudayaan lama seperti cerita rakyat mulai tergeser disebabkan oleh masuknya budaya asing. Rasa cinta terhadap kebudayaan mulai bergeser sebab semakin banyaknya masyarakat yang menirukan budaya asing, lebih banyak masyarakat yang lebih memilih membaca cerita asing dari pada budaya budayanya sendiri.

Nilai-nilai yang terkandung di dalam cerita rakyat Jambi sangat beragam, diantaranya nilai karakter, nilai budaya, nilai sosial, nilai psikologi, nilai pendidikan, dan nilai moral. Nilai moral merupakan nilai yang berhubungan dengan norma-norma yang ada di dalam masyarakat."Nilai moral adalah nilainilai yang mengacu pada baik buruknya 
tindakan manusia sebagai manusia" (Sulistyorini, 2017: 51). Dapat diartikan bahwa nilai moral berkaitan dengan norma hidup mengenai baik buruknya tindakan seseorang.

Nilai moral, baik digunakan dalam kehidupan bermasyarakat dan bagi dunia Pendidikan. Cerita rakyat yang di dalamnya terdapat nilai moral dapat dijadikan bahan pembelajaran bagi siswa untuk bersikap dalam kehidupan atau kondisi-kondisi tertentu. Cerita rakyat dapat dijadikan bahan pembelajaran karena di dalamnya terdapat nilai-nilai yang baik salah satunya adalah nilai moral.

Thabran Kahar adalah seorang penulis buku Cerita Rakyat Daerah Jambi. Salah satu buku yang diterbitkan yaitu, Cerita Rakyat Daerah Jambi yang berisi 20 cerita rakyat di dalamnya. Dicetak pada tahun 1979, diterbitkan oleh Proyek Penerbit Buku Bacaan dan Sastra Indonesia dan Daerah dengan jumlah 168 halaman.

Beberapa pertimbangan penelitian mengenai nilai moral dalam cerita rakyat Jambi dilakukan adalah sebagai berikut.

1. Cerita rakyat Jambi merupakan warisan budaya lisan turun temurun yang dimiliki oleh Provinsi Jambi yang berisi nilai luhur budaya.

2. Terbukanya ilmu pengetahuan dan teknologi yang semakin maju maka budaya Jambi sudah mulai tergerus dan punah.

3. Budayawan Jambi yakni Junaidi T. Noer dalam seminar bahasa yang dilangsungkan pada 2017 lalu, mungungkapkan kerisauan akan tergerusnya nilai-nilai dalam budaya masyarakat Jambi akibat masuknya budaya asing dan teknologi informasi.
4. Cerita rakyat Jambi memuat nilai moral dalam cerita yang akan jadi bacaan masyarakat yang dapat menuntun sikap nilai moral dalam kehidupan.

Berdasarkan paparan di atas, maka penelitian ini dilakukan. Adapun judul penelitian ini adalah Nilai Moral dari Aspek Hubungan Manusia dengan Manusia dalam Kumpulan Cerita Rakyat Jambi Karya Thabran Kahar.

Berdasarkan latar belakang yang telah dipaparkan, teridenfikasi bahwa nilai moral memiliki cakupan yang cukup luas. Nilai moral memiliki empat wujud. Menurut Nurgiyantoro (2010: 323-324). Moral dapat dikelompokan menjadi beberapa persoalan kehidupan antara lain:

1. Nilai moral hubungan manusia dengan diri sendiri.

2. Nilai moral hubungan manusia dengan manusia lain.

3. Nilai moral hubungan manusia dengan lingkungan alam.

4. Nilai moral hubungan manusia dengan Tuhan Yang Maha Esa.

Penelitian ini berfokus pada nilai moral antar manusia dengan manusia lain yang mencangkup tujuh aspek. Menurut Nugriyantoro (2010: 323-324) nilai moral hubungan manusia dengan manusia lain mencangkupi tujuah aspek yakni: (1) peduli sesama, (2) tolong menolong, (3) bermusyawarah, (4) hidup rukun, (5) pemaaf, (6) tepat janji, (7) menghargai orang lain. Ketujuh aspek nilai moral tersebut akan dianalisis dalam Kumpulan Cerita Rakyat Daerah Jambi karya Thabran Kahar.

Berdasarkan fokus permasalahan di atas, maka pertanyaan penelitian ini sebagai berikut.

1. Bagaimanakah nilai moral manusia dengan manusia lain dalam wujud 
tolong-menolong pada kumpulan Cerita Rakyat Daerah Jambi karya Thabran Kahar?

2. Bagaimanakah nilai moral manusia dengan manusia lain dalam wujud pemaaf pada kumpulan Cerita Rakyat Daerah Jambi karya Thabran Kahar?

3. Bagaimanakah nilai moral manusia dengan manusia lain dalam wujud tepat janji pada kumpulan Cerita Rakyat Daerah Jambi karya Thabran Kahar?

Adapun tujuan penelitian ini, sebagai berikut.

1. Mendeskripsikan nilai moral antara manusia dengan manusia lain dalam wujud tolong-menolong yang terdapat dalam kumpulan Cerita Rakyat Daerah Jambi karya Thabran Kahar.

2. Mendeskripsikan nilai moral antara manusia dengan manusia lain dalam wujud pemaaf yang terdapat dalam kumpulan cerita rakyat Jambi karya Thabran Kahar.

3. Mendsekripsikan nilai moral anatara manusia dengan manusia lain dalam wujud tepat janji yang terdapat dalam kumpulan Cerita Rakyat Daerah Jambi karya Thabran Kahar.

Adapun manfaat penelitian ini adalah sebagai berikut.

Secara teoretis, hasil penelitian ini diharapkan bermanfaat untuk:

1. menambah wawasan dan pengetahuan sastra khususnya fiksi yang berhubungan dengan cerita rakyat;

2. mengembangkan sastra lisan yang sudah dituliskan dan bacaan yang berhubungan dengan nilai moral.

Secara praktis, hasil penelitian ini diharapkan bermanfaat untuk:

1. penikmat sastra dapat dijadikan bahan acuan pembaca dalam mengapresiasi nilai moral dalam kumpul Cerita
Rakyat Daerah Jambi Karya Thabran Kahar;

2. peneliti selanjutnya

3. dapat dijadikan sebagai bahan referensi bagi penelitian selanjutnya;

4. sastrawan dapat menulis karya yang bermutu yang dapat memberi nilainilai positif yang dapat dicontoh atau diterapkan dalam kehidupan seharihari;

5. dunia pendidikan dapat dijadikan bahan ajar guru untuk siswa/i mengenai nilai moral dari cerita rakyat untuk bersikap dalam kehidupan terlebih pembelajaran dalam hal sastra tradisional;

6. mahasiswa dapat menambah wawasan mengenai sastra lisan khususnya cerita rakyat.

\section{METODE PENELITIAN}

Dalam penelitian sastra terdapat beberapa pendekatan dalam menganalisisnya. Perbedaan pendekatan inilah yang kemudian memunculkan adanya berbagai jenis penelitian sastra (Rahima, 2017:1). Selain itu, jenis penelitian dapat menggambarkan bagaimana peneliti menyelesaikan masalah penelitiannya. "Jenis penelitian adalah cara yang digunakan seorang peneliti di dalam usaha memecahkan masalah yang diteliti" (Siswanto, 2010: $55)$.

Penelitian ini merupakan penelitian sastra. Jenis penelitian ini adalah deskriptif kualitatif. "Deksritif adalah prosedur pemecahan masalah dengan mengambarkan atau melukiskan keadaan subjek atau objek penelitian pada saat sekarang berdasarkan faktafakta yang tampak atau sebagaimana adanya" (Nawawi dalam Siswantoro, 2010: 56).

Jenis penelitian kualitatif merupakan analisis proses dan proses 
berpikir secara induktif yang berkaitan dengan dinamika hubungan antar fenomena yang diamati, dan senantiasa menggunakan logika ilmiah. "Jenis penelitian kualitatif bertujuan mengembangkan konsep sensitivitas pada masalah yang dihadapi. Mengembangkan realitas yang berkaitan dengan penelusuran teori" (Gunawan, 2015: 80).

Data penelitian ini berupa kutipan-kutipan yang berkaitan dengan nilai moral hubungan manusia dengan manusia lain yang terdapat dalam cerita Kumpulan Cerita Rakya Daerah Jambi karya Thabran Kahar.

Sumber data adalah data yang diperoleh dari sumber yang akan diteliti. "Sumber data terkait dengan subjek penelitian dari mana data diperoleh" (Siswantoro, 2010 :72). Sumber data adalah dimana penelitian mengambil data penelitian tersebut. Sumber data dalam penelitian ini adalah Kumpulan Cerita Rakyat Daerah Jambi Karya Thbabran Kahar.

"Teknik pengumpulan data merupakan langkah yang paling strategis dalam penelitian, karena tujuan utama dari penelitian ini adalah data" (Sugiyono, 2016: 224). “Teknik pengumpulan data merupakan bagian penting dari proses penelitian. Begitu sentral peran pengumpulan data sehingga kualitas penelitian bergantung padanya" (Siswantoro, 2010: 73). Teknik pengumpulan data dalam penelitian ini mengunakan teknik studi pustaka dan dokumentasi.

Dokumen tentang orang atau kelompok orang, peristiwa, atau kejadian dalam situasi sosial yang sesuia dan terkait dengan fokus penelitian adalah sumber informasi yang sangat berguna dalam penelitian kualitatif. Dokumen itu dapat berbentuk teks tertulis, artefacts, gambar, maupun foto (Yusuf, 2014 :391), yang difokuskan untuk mengumpulkan serta menganalisis data temuan yang berkaitan dengan nilai moral hubungan manuisa dengan manusia yang terdapat dalam Kumpulan Cerita Rakyat Daerah Jambi Karya Thabran Kahar.

Adapun teknik pengumpulan data yang dilakukan sebagai berikut.

1. Penulis membaca kumpulan Cerita Rakyat Daerah Jambi karya Tabran Kahar dengan saksama

2. Penulis menandai bagian-bagian teks yang berhubungan dengan nilai moral yang berkaitan dengan nilai moral manusia dengan manusia lain yang mencakupi tujuh wujud: (1) Pedulis sesama, (2) tolong-menolong, (3) bermusyawarah, (4) hidup rukun, (5) pemaaf, (6) tepat janji, dan (7) menghargai orang lain.

3. Kemudian penulis mengumpulkan data yang berhubungan dengan nilai moral dalam Kumpulan Cerita Rakyat Daerah Jambi karya Thabran Kahar.

4. Penulis mengelompokan data dengan teori yang sesuai dengan nilai moral manusia dengan manusia lain yang meliputi tujuh aspek (1) Peduli sesama, (2) tolong-menolong, (3) bermusyawarah, (4) hidup rukun, (5) pemaaf, (6) tepat janji, dan (7) menghargai orang lain.

"Analisis data adalah proses mengorganisasikan dan mengurutkan data ke dalam pola, kategori, dan satuan uraian dasar sehingga dapat ditemukan tema dan dapat dirumuskan hipotesis kerja seperti yang disarankan oleh data" (Ismawati. 2012 :15-16). Teknik analisis data yang digunakan untuk menganalisis data nilai moral manusia dengan manusia lain yang meliputi tujuh aspek (1) peduli sesama, (2) tolong-menolong, bermusyawarah, (4) hidup rukun, 
pemaaf, (6) tepat janji, dan (7) menghargai orang lain. Pada penelitian ini, penulis menggunakan teknik analisis data yang mengacu pada teknik analisis data oleh Siswantoro (2010: 81).

Kegiatan analisis data dilakukan dengan langkah-langkah sebagai berikut.

1. Data yang telah dikelompokkan pada data di atas, kemudian ditabulasikan ke dalam tabel tabulasi data.

2. Data yang sudah ditabulasikan sesuai dengan kerangka teori yang berkaitan dengan masalah penelitian, selanjutnya penulis deskripsikan.

3. Langkah berikutnya penulis melakukan keabsaan data melalui triagulasi data, melalui triagulasi data dengan cara memasukkan data yang penulis dapat ke dalam tabel tabulasi data. Keabsaan data ada tiga, yaitu:

1) mengabsahkan data dengan teori,

2) mengbsahkan data dengan metode,

3) menghabsakan data dengan pakar atau pembimbing, dan

4. Langkah terakhir penulis merumuskan kesimpulan.

\section{HASIL DAN PEMBAHASAN}

Berdasarkan hasil analisis data yang telah dilakukan ditemukan aspek nilai moral dalam kumpulan Cerita Rakyat Daerah Jambi Karya Thabran Kahar. Aspek nilai moral tersebut berupa nilai moral manusia dengan manusia lain yang meliputi: peduli sesama, tolongmenolong, bermusyawarah, hidup rukun, pemaaf, tepat janji, dan menghargai orang lain. Dari 20 Cerita Rakyat Daerah Jambi karya Thabran Kahar, ditemukan sebanyak 60 kutipan dari 7 aspek yang dianalisis, diantaranya sebagai berikut.

\section{Aspek Tolong-menolong}

Aspek Tolong-menolong dalam kumpulan Cerita Rakyat Daerah Jambi
Karya Thabran Kahar dapat digambarkan bahwa tokoh-tokoh dalam cerita memiliki sikap tolong-menolong saat melihat orang lain dalam kesusahan atau kesukaran dengan lekas membantu tanpa pamrih. Nilai moral aspek tolongmenolong dalam kumpulan Cerita Rakyat Daerah Jambi terdapat sebanyak 12 kutipan.

\section{Aspek Pemaaf}

Aspek pemaaf dalam kumpulan Cerita Rakyat Daerah Jambi Karya Thabran Kahar dapat digambarkan bahwa tokoh-tokoh dalam cerita memiliki sikap pemaaf yang mampu memaafkan kesalahan orang lain dengan ikhlas tanpa memiliki rasa dendam. Nilai moral aspek pemaaf dalam kumpulan Cerita Rakyat Daerah Jambi terdapat sebanyak 6 kutipan.

\section{Aspek Tepat Janji}

Aspek tepat janji dalam kumpulan Cerita Rakyat Daerah Jambi Karya Thabran Kahar dapat digambarkan bahwa tokoh-tokoh dalam cerita memiliki sikap tepat janji ketika berbicara dan bertindak mampu membuktikan kebenarannya sehingga mendapatkan kepercayaan dari orang lain. Nilai moral aspek tepat janji dalam kumpulan Cerita Rakyat Daerah Jambi terdapat sebanyak 4 kutipan.

Penelitian ini membahas tentang aspek-aspek perwujudan dari nilai-nilai moral dalam kumpulan Cerita Rakyat Daerah Jambi karya Thabran Kahar. Berikut tujuh aspek nilai moral yang dibahas dalam kumpulan Cerita Rakyat Daerah Jambi karya Thabran Kahar.

\section{a. Aspek Tolong-Menolong}

Tolong menolong berarti tindakan saling menolong yang wujudnya saling membantu dan meringkan beban untuk melakukan sesuatu."Saling menolong 
adalah sikap dan praktik membantu sesama. Suatu masyarakat akan nyaman dan sejahtera, jika dalam kehidupan masyarakatnya tertanam sikap tolong menolong dan saling membantu satu sama lain" (Yusmansyah, 2006: 89). Manusia merupakan mahluk sosial yang membutuhkan bantuan orang lain. Berikut akan dipaparkan contoh ungkapan yang menggambarkan nilai moral aspek tolong-menolong

Kutipan 1

Namanya Tuan Putri Syarifah Alam yang disayangi rakyatnya. Beliau mempunyai dubalang-dubalang yang gagah berani dan sakti-sakti. Semuanya sanggup bertenteng dada berpagar betis demi keselamatan rajanya wanita yang cantik dan ayu itu. (Keramat Paseban Tuan Putri Syarifah Alam :17)

Dalam kutipan 1 terdapat nilai moral aspek tolong-menolong tokoh para Dubalang. Kutipan tersebut dianalisis berdasarkan dialog para tokoh dalam cerita, yang mengandung nilai moral pada kutipan Semuanya sanggup bertenteng dada berpagar betis demi keselamatan rajanya wanita yang cantik dan ayu itu. Kutipan tersebut termasuk nilai moral tolong-menolong karena pada kutipan tersebut menjelaskan para Dubalang bersedia mengorbankan jiwanya untuk Tuan Puteri. Mereka siap membantu dan membela Tuan Puteri saat menghadapi ancaman dari orang jahat. Perilaku para Dubalang tersebut mencerminkan sikap saling tolongmenolong. Sikap tokoh para Dubalang tersebut terdapat dalam kehidupan nyata dan dapat dijadikan contoh teladan dalam kehidupan sehari-hari.

Kutipan 2

Lelaki tua itu namanya Tuan Patih. Ia seorang lelaki tua yang belum beristri.
Apa sebabnya pada umur setua itu ia tak juga beristri, tak seorang pun yang tahu. Ia seorang lelaki yang terbiasa hidup menyendiri diladangnya di tengah rimba.

Kepada dia inilah istri raja tadi menitipkan anak perempuan yang baru lahir itu untuk dipelihara. Nasib baik lelaki itu menerima dan mengabulkan kehendak perempuan istri raja itu bersama Tuan Patih. Anak perempuan itu pun dibesarkannya dengan penuh kesabaran dan kasih sayang yang luar biasa hingga besar. (Nenek Putih :23)

Dalam kutipan 2 terdapat nilai moral aspek tolong-menolong tokoh Patih. Kutipan tersebut dianalisis berdasarkan dialog para tokoh dalam cerita, yang mengandung nilai moral pada kutipan Kepada dia inilah istri raja tadi menitipkan anak perempuan yang baru lahir itu untuk dipelihara. Nasib baik lelaki itu menerima dan mengabulkan kehendak perempuan istri raja itu bersama Tuan Patih. Kutipan tersebut termasuk nilai moral tolong-menolong karena pada kutipan tersebut menjelaskan Patih bersedia membantu isteri raja. Ia menerima bayi dari isteri raja, agar bayi tersebut tidak dibunuh oleh raja. Perilaku Patih tersebut mencerminkan sikap saling tolongmenolong. Sikap tokoh Patih tersebut terdapat dalam kehidupan nyata dan dapat dijadikan contoh teladan dalam kehidupan sehari-hari.

\section{b. Aspek Pemaaf}

Memberi maaf haruslah disertai dengan ketulusan hati dan berlapang dada, sehingga tidak tersisa rasa dendam atau keinginan untuk membalasnya. "Sesungguhnya setiap manusia mencintai sifat pemaaf. Pemaaf adalah puncak keangungan dari sifat-sifat yang mulia, yang merupakan tempat bermuaranya 
sifat sabar, menahan amarah, ikhlas dan lapang dada" (Sugito, 2014: 134). Pemaaf merupakan sifat dari jiwa-jiwa yang tinggi setiap manusia hendaknya memiliki sefat pemaaf agar tercipta kedamaian dalam kehidupan bemasyarakat. Berikut akan dipaparkan contoh ungkapan yang menggambarkan nilai moral aspek pemaaf.

Kutipan 3

Pandai besi itu terkejut bukan main. Mukanya pucat seketika dan segera menyembah, menyimpuh ke hadapan Datuk Mangkuto Sati. "Datuk Mangkuto Sati melihat kepada pandai besi itu. Kasihannya segera terasa. Tek tega hatinya untuk menikam pisau itu kepada pandai besi yang bodoh itu. (Bukit Bulan :66)

Dalam kutipan 3 terdapat nilai moral aspek pemaaf tokoh Datuk Mangkuto Sati. Kutipan tersebut dianalisis berdasarkan dialog para tokoh dalam cerita, yang mengandung nilai moral pada kutipan Datuk Mangkuto Sati melihat kepada pandai besi itu. Kasihannya segera terasa. Tek tega hatinya untuk menikam pisau itu kepada pandai besi yang bodoh itu. Kutipan tersebut termasuk nilai moral pemaaf karena pada kutipan tersebut menjelaskan Datuk Mangkuto Sati mengurungkan niatnya untuk menikam pandai besi yang ingin memcoba membunuhnya. Datuk Mangkuto Sati merasa iba dan meaafkan pandai besi tersebut. Perilaku tokoh Datuk Mangkuto Sati tersebut mencerminkan sikap pemaaf. Sikap Datuk Mangkuto Sati tersebut terdapat dalam kehidupan nyata dan dapat dijadikan contoh teladan dalam kehidupan sehari-hari.

Kutipan 4
Hulubalang Tengkorak Batu bersungutsungut. Barulah pada tikaman yang ketiga hulubalang keramat tersebut menoleh ke belakang. "Amboi, kalian rupanya!" kata Hulubalang Tengkorak Batu kepada Serempak dan Si Ceren. "Apa sebabnya itu kalian lakukan terhadapku? Naiklah dulu kita ke rumah, bertanya tentu selepas lelah." Maka naiklah ketiga lelaki itu ke rumah. (Hulubalang Tengkorak Batu :78)

Dalam kutipan 4 terdapat nilai moral aspek pemaaf tokoh Tengkorak Batu. Kutipan tersebut dianalisis berdasarkan dialog para tokoh dalam cerita, yang mengandung nilai moral pada kutipan Apa sebabnya itu kalian lakukan terhadapku? Naiklah dulu kita ke rumah, bertanya tentu selepas lelah." Kutipan tersebut termasuk nilai moral pemaaf karena pada kutipan tersebut menjelaskan Tengkorak Batu yang tidak membalas tikaman Serempak dan Ceren. Tengkorak Batu tidak menaruh denda sedikitpun atas perbuatan Serempak dan Ceren, ia dengan berbaik hati mempersilahkan mereka berdua beristirahat di rumahnya. Perilaku tokoh Tengkorak Batu tersebut mencerminkan sikap pemaaf. Sika Tengkorak Batu tersebut terdapat dalam kehidupan nyata dan dapat dijadikan contoh teladan dalam kehidupan sehari-hari.

\section{c. Aspek Tepat Janji}

Dalam kehidupan manusia tidak terlepas dengan kesepakatan atau janji yang dilakukan bersama, baik antar individu, kelompok maupun yang lain. "Tepat janji merupakan salah satu perilaku yang harus dimiliki oleh setiap orang, tempat janji merupakan kunci untuk menarik kepercayaan orang lain (Syarbini, 2013: 47). Janji kata yang bentuknya sepeleh namu jika hal itu tidak 
dilakukan bisa berakibat buruk pada diri manusia. Berikut akan dipaparkan contoh ungkapan yang menggambarkan nilai moral aspek tepat janji.

Kutipan 5

"Pak guru," katanya kepada seorang laki-laki yang menjadi guru mengaji di rumah itu, "kalau nanti salah seorang dari anak mengaji pak guru yang lakilaki duluan turun, maka dialah yang akan menjadi suami saya." Tentu saja pak guru itu sangat heran. Pertama anak-anak asuhnya masih kecil-kecil, berkisar antara umur lima sampai tujuh tahun. Kedua Tuan Puti itu sendiri umurnya dilihat daripada rupa hampir sepuluh tahun. Pak guru tak mengambil pusing amat akan hal tersebut. Begitulah akhirnya Tuan Puti itu kawin juga dengan anak yang mengaji tadi. (Nenek Putih :26)

Dalam kutipan 5 terdapat nilai moral aspek tepat janji tokoh Tuan Puti. Kutipan tersebut dianalisis berdasarkan dialog para tokoh dalam cerita, yang mengandung nilai moral pada kutipan kalau nanti salah seorang dari anak mengaji pak guru yang laki-laki duluan turun, maka dialah yang akan menjadi suami saya dan Begitulah akhirnya Tuan Puti itu kawin juga dengan anak yang mengaji tadi. Kutipan tersebut termasuk nilai moral tepat janji karena pada kutipan tersebut menjelaskan Tuan Puti berikrar kepada pak guru bahwa ia akan menikahi salah satu dari murid pak guru. Tuan Puti menepai janjinya dan akhirnya menikahi seorang murid dari pak guru. Perilaku tokoh Tuan Puti tersebut mencerminkan sikap menepati Janji. Sikap Tuan Puti tersebut terdapat dalam kehidupan nyata dan dapat dijadikan contoh teladan dalam kehidupan sehari-hari.
Kutipan 6

"Tentu Datuk sudah mengerti," kata Datuk German Tembaga kepada raja Johor. "Adat orang kalah harus melepaskan yang datuk tawan dan memberikan yang kami pinta. Lepaskanlah permainsuri raja kami dan berikanlah tanda persembahan!" Raja Johor pun melepaskan permainsuri raja Jambi dan dan disamping itu diserahkannya puterinya sendiri Putri Intan Selasih sebagai persembahan pihaknya yang kalah. (Pulau Jur :41)

Dalam kutipan 6, terdapat nilai moral aspek tepat janji tokoh Raja Johor. Kutipan tersebut dianalisis berdasarkan dialog para tokoh dalam cerita, yang mengandung nilai moral pada kutipan Adat orang kalah harus melepaskan yang datuk tawan dan memberikan yang kami pinta dan Raja Johor pun melepaskan permainsuri raja Jambi dan dan disamping itu diserahkannya puterinya sendiri Putri Intan Selasih sebagai persembahan pihaknya yang kalah. Kutipan tersebut termasuk nilai moral tepat janji karena pada kutipan tersebut menjelaskan Raja Johor diminta untuk melepaskan tawanannya karena ia sudah dikalahkan oleh Datuk German Tembaga. Raja Johor pun akhirnya melepaskan tawanannya tersebut. Perilaku tokoh Raja Johor tersebut mencerminkan sikap menepati Janji. Sikap Raja Johor tersebut terdapat dalam kehidupan nyata dan dapat dijadikan contoh teladan dalam kehidupan seharihari.

\section{SIMPULAN}

Berdasarkan hasil penelitian dan pembahasan yang telah dijabarkan, maka dapat disimpulkan bahwa terdapat tujuh aspek nilai moral di dalam kumpulan 
Cerita Rakyat Daerah Jambi Karya Thabran Kahar. Ketujuh aspek tersebut adalah sebagai berikut.

1. Aspek tolong-menolong dalam kumpulan Cerita Rakyat Daerah Jambi Karya Thabran Kahar terlihat dari dialog para tokoh dalam cerita tersebut yang mana saling bahumembahu, membantu orang yang sedang kesusahan dengan ikhlas tanpa pamrih. Kutipan yang berkaitan dengan aspek tolong-menolong dalam kumpulan Cerita Rakyat Daerah Jambi terdapat 12 kutipan.

2. Aspek pemaaf dalam kumpulan Cerita Rakyat Daerah Jambi Karya Thabran Kahar terlihat dari dialog para tokoh dalam cerita tersebut yang mana tidak pernah menyimpan perasaan dendam, tidak ingin membalas perbuatan buruk orang lain, dan mampu mengendalikan diri dari rasa marah. Kutipan yang berkaitan dengan aspek pemaaf dalam kumpulan Cerita Rakyat Daerah Jambi terdapat 6 kutipan.

3. Aspek tepat janji dalam kumpulan Cerita Rakyat Daerah Jambi Karya Thabran Kahar terlihat dari dialog para tokoh dalam cerita tersebut yang mana selalu amanah saat diberikan sebuah tanggung jawab, tidak pernah berdusta dengan ucapannya, dan mampu membuktikan ikrarnya. Kutipan yang berkaitan dengan aspek tepat janji dalam kumpulan Cerita Rakyat Daerah Jambi terdapat 4 kutipan.

\section{Saran}

Berdasarkan kesimpulan yang telah disampaikan, maka diharapkan pada masa yang akan datang kepada peneliti lain agar dapat melakukan penelitian yang lebih mendalam lagi mengenai aspek nilai moral ini.
Adapun beberapa saran yang disampaikan adalah sebagai berikut.

1. Disarankan dengan penelitian ini dapat menambah wawasan pembaca mengenai aspek nilai moral yang terkandung dalam suatu karya sastra.

2. Disarankan kepada para sastrawan agar terus dapat menciptakan cerita rakyat-cerita rakyat yang sarat akan nilai-nilai moral sehingga dapat menjadi teladan bagi pembaca.

3. Disarankan bagi peneliti yang tertarik untuk meneliti aspek nilai moral pada sebuah cerita rakyat, sebaiknya memilih cerita rakyat yang dapat mengangkat kearifan lokal suatu daerah.

\section{DAFTAR PUSTAKA}

Danandjaja, James. (2002). Foklor Indonesia. Jakarta: Pustaka Utama Grafiti.

Gunawan, Imam. (2015). Metode Penelitian Teori dan Praktik. Jakarta: Bumi Aksara.

Iswawati, Esti. (2012). Metode Penelitian Pendidikan Bahasa \& Sastra. Yogyakarta: Ombak.

Nurgiyantoro, Burhan. (2010). Teori Pengkajian Fiksi. Yogyakarta: Gadjah Mada.

Rahima, A. (2017). Literature Reception (a Conceptual Overview). Jurnal Ilmiah Dikdaya, 6(1), 1-16.

Rahima, A. (2017). Interpretasi Makna Simbolik Ungkapan Tradisional Seloko Hukum Adat Melayu Jambi. Jurnal Ilmiah Universitas Batanghari Jambi, 17(1), 250267.

Siswantoro. (2010). Metode Penelitian Sastra. Yogyakarta: Pustaka Belajar.

Sugito. (2014). Jadilah Pemaaf dan Baikan Orang -orang Bodoh. 
Jakarta: PT Elex Media Yusmansyah, (2006). Akidah dan Akhlak.

Komputindo. Bandung: Penerbit

Sugiyono. (2016). Metode Penelitian GrasindoMedia Pratama.

Kuantitatif dan Kualitatif. Yusuf, Muri. (2017). Metode Penelitian:

Bandung: Alfabeta. Kuantitatif, Kualitatif, Dan

Penelitian Gabungan. Jakarta

:Kencana.

Nilai Moral dari Aspek Hubungan Manusia dengan Manusia dalam Kumpulan Cerita Rakyat Daerah Jambi Karya Thabran Kahar 